\title{
The Ethics of Direct Primary Care
}

\author{
Andy Wible \\ Department of Arts and Humanities, Muskegon Community College, Muskegon, USA \\ Email: andy.wible@muskegoncc.edu
}

How to cite this paper: Wible, A. (2019) The Ethics of Direct Primary Care. Open Journal of Philosophy, 9, 35-44. https://doi.org/10.4236/ojpp.2019.91003

Received: December 27, 2018

Accepted: February 16, 2019

Published: February 19, 2019

Copyright (c) 2019 by author(s) and Scientific Research Publishing Inc. This work is licensed under the Creative Commons Attribution International License (CC BY 4.0).

http://creativecommons.org/licenses/by/4.0/

\begin{abstract}
Direct primary care (DPC) is a market based approach to providing medical care. Patients avoid insurance and directly pay a monthly membership type of fee to physicians for unlimited access. DPC practices have been growing throughout the United States by claiming to be better for patients and primary care physicians. This paper looks into the ethical implications of such practices and explores future moral concerns if DPC continues to expand. Finally, from a societal perspective, regulated universal coverage, as provided in countries such as Japan, is examined as a way to achieve most of the benefits of DPC while avoiding many of the problems.
\end{abstract}

\section{Keywords}

Direct Primary Care, Medical Ethics, Primary Care, Universal Health Care, Justice

\section{Introduction}

Direct primary care (DPC) is a newer phenomenon in the United States where patients directly pay their doctors a monthly fee for all of their primary care much like that they pay for their gym membership. For that monthly fee, patients can go to their physicians as often as they would like. At about 1000, the number of DPC practitioners is small, but growing (Eskew \& Kathleen, 2015; Ramsey, 2017). This article will examine some of the moral issues with direct primary care, and additional moral implications to consider if it continues to expand, and what DPC teaches us about reforming the US healthcare system.

Fewer physicians are going into primary care for several reasons. Incomes have gone down and responsibilities have increased. Primary Care Physicians earn on average 100,000 dollars less than specialists (Medscape, 2017). Physicians are having to see more patients for shorter periods of time, facing higher administrative costs, and receiving less reimbursement for their services. They 
spend less time diagnosing and treating patients, because they spend many hours figuring out insurance codes, filling out paper work, and arguing with Medicaid, Medicare, and private insurers over proper care. A recent study in the Annals of Medicine found that physicians spend nearly twice as much time on paperwork as they do on patient care (Sinsky et al., 2016). Rather than burning out, retiring, or practicing another kind of medicine, some primary care physicians have looked for another way to provide primary care.

\section{Economic Advantages}

DPC is the classic free market efficiency story of taking out the middle man to provide a better and cheaper product. Direct primary care is a subscription based practice that charges a reasonable monthly fee of $60-150$ dollars a month to provide primary care for patients. It is direct because insurance is not involved. The profits, restrictions, and bureaucracy of insurance are avoided. Overhead costs are lessened by as much as $40 \%$, and physicians no longer have to wrestle with insurers to provide good care (Zamosky, 2014). Physicians get to focus on patients rather than third party providers, see fewer patients, and often earn a higher salary (Zamosky, 2014). In addition, patients don't have to fight with insurers to get treatments covered.

\section{Medical Advantages}

One big medical advantage of DPC is that patients get to see their doctor when they want and as often as they would like. Same day and next day office visits are standard, and all office visits and basic tests are covered by the monthly membership fee. Physicians spend more time with patients, often 2 - 4 times as long. Rather than 10 - 15 minutes per visit, patients get 30 - 60 minutes due to DPC physicians seeing about a third as many patients as traditional practitioners (Ramsey, 2017). The number of primary care visits per year is higher as well. The average is 4 per year compared to 2 per year for non-DPC practices (Eskew \& Kathleen, 2015). Physicians are able to maintain their income with the steady monthly payments of on average 600 patients, rather than intermittent payments from 2000 or more. The revenue is generally lower than a fee for service model, but there are lower overheads since insurance does not need to be billed. Practices commonly spend up to $40 \%$ on administrative costs and much of that comes from billing and consulting third party insurance companies. This money and time can be used on healthcare instead with DPC (Direct Primary Care Coalition, 2013).

Does DPC translate to better care? More research is needed since most practices are young and small, but one small study found patients were admitted to the hospital over 50\% less often and were readmitted over $90 \%$ less often for myocardial infarction, congestive heart failure, and pneumonia (Klemes et al., 2012). Another study of Qliance, a large direct primary care group in Seattle, found that there were $35 \%$ fewer hospitalizations, $65 \%$ fewer emergency visits, 
and 66\% fewer specialist visits (Page, 2013). So, it may be that DPC results in better preventative care, better management of chronic conditions, and better post-hospital care. Greater patient access and connection does seem to be correlated to better care.

\section{Ethical Concerns: Market Pressures and Failures}

Even though there is evidence of greater economic efficiencies and improved patient care there are ethical concerns. The concerns stem mainly from what are often called "market failures". These are harms and injustices that can arise in any unregulated profit driven free market system. Individuals are unjustly harmed and the system is worse off or unjust from a broader ethical point of view. The fairlures are particularly troubling morally in health care, because people's well-being is so directly affected.

The first set of concerns focus on patients that are excluded from DPC. When a practice converts to direct primary care, it often leads to 1200 or more patients per physician that need to find a new primary care physician. Finding a new physician is never enjoyable and is particularly challenging for many due to a shortage of primary care physicians particularly in rural areas and areas with high numbers of racial and ethnic minorities (AAMC, 2017).

Primary care physicians are usually who patients see most and a strong relationship often forms. Breaking this relationship can cause hardship for the patient and forming a new relationship takes time. Physicians are to look after the best interests of their patients and care for these patients can suffer during this transition. Most practices try to give adequate time for patients to find new physicians and some states have laws requiring a specific amount of time for patients to find a new physician.

One reply to this concern is that this harm caused by conversion seems comparable to that caused by physician offices that decide to no longer take the insurance that some patients carry. As long as there is transparency and sufficient time is given for patients to transition, deciding not to take certain insurance is seen as acceptable even though it is a burden to some patients. Physicians don't have an obligation to see every patient who wants to see them. If severe primary care shortages exist, then physicians do have a greater moral obligation to keep patients until other accommodations can be arranged.

From a broader perspective, the public health system is also stressed during direct primary care conversions. The number of physicians going into primary care is at an all-time low and there are more patients needing primary care as baby boomers grow older and the age of the overall population rises (Porter, 2015). As a result, the public suffers even if the patients who stay in DPC end up getting better care. Exacerbating this healthcare problem goes against a utilitarian obligation to the greater good.

DPC advocates reply that the practice will cause more physicians to go into primary care (Brekke, 2016). Primary care physicians don't like the high patient 
loads, long hours, and low pay. DPC provides close relationships, less paperwork, and potentially more time or better pay. Even if this ends up being true, the result for public welfare may result in shortages of physicians in other specialties unless the overall number of physicians increases.

Justice is another value that seems to apply to converting practices to DPC. DPC physicians have an interest in eliminating the old, sick, and poor from their practices. Is it right to discriminate by the ability to pay? DPC does not seem to have the same problem as other types of concierge medicine that bills insurance and then adds an additional payment for special treatment for those who can afford it. Because insurance is avoided, the treatment and payment is the same for everyone in DPC. DPC is problematic due to those who don't get DPC coverage. Patients who cannot afford DPC have fewer healthcare options and often suffer from worse care. If DPC advocates are right that DPC practices will be attractive to physicians, then the best doctors will go into such practices and will abandon lower-income patients unable to pay the monthly fee. The Affordable Care Act, before being amended for 2019, required people to have insurance, so lower income patients cannot drop insurance all together for DPC. After all, insurance for specialist care, emergency care, and hospitalization care is still needed.

DPC is a free market solution to healthcare. Markets don't guarantee uniform outcomes. Should direct primary care physicians be obligated to care for those who cannot pay? There might be some obligation to provide some pro bono care, but this obligation seems limited for a private business. It is the government that has the primary obligation if one exists. The United States legally requires that life-saving care be provided by emergency rooms, but not the preventative and chronic care that primary care provides. This is even as a 2009 Harvard study shows that approximately 45,000 people die yearly because they lack health insurance (Wilper et al., 2009). We should not blame DPC physicians for not taking care of such patients. The system is responsible for their poorer or non-existent care.

State governments have attempted to use DPC for the neediest patients. DPC has been used in several pilot cases for patients that have Medicaid. One problem that occurred in Washington State is that Medicaid law does not allow payments to physicians when the service is unused. At Qliance, 25\% of Medicaid patients signed up for DPC didn't use the services in the first year. Thus, Medicaid asked for repayment of those monthly dues. Qliance, a large practice on the forefront of DPC, closed its offices in 2017 due to this practice (Krivich, 2017). Medicaid law will need to change if DPC is to be used more broadly in the future.

There are other types of discrimination and lack of care that may be more directly attributable to DPC. For example, will physicians encourage their favorite patients to stay and their hated ones to leave? In the fee for service model, sicker patients create more income. In DPC, healthier patients create more income. DPC physicians have an incentive to try to get healthier patients and they tend to charge younger people a smaller fee. On the flip side, younger healthier pa- 
tients have less of an incentive to choose DPC. They just don't see themselves using it enough. Direct primary care practices will need to find a price point that gets the right mix of patients. It will be one that entices young and healthy patients but that excludes many of the sick and old as health insurance companies formerly set for premiums.

DPC practices do tend to charge patients over 50 a slightly higher monthly fee because they are expected to make greater use of care. They currently don't do the same and charge a higher fee for people who are sick or are more likely to be sick. Yet, the market might lead to that practice if more care is needed and the number of such patients needs to be limited. The ACA says that insurance providers can no longer charge people with preexisting conditions a higher fee (Insurance companies agreed to this change when younger people were required to get insurance). The moral reasoning is that it is unjust to charge people more due to the bad luck of being sick. Is it morally permissible to charge elderly people more due to the good luck of being older?

DPC providers are attempting to make sure that they are allowed to take the patients that they want without government oversight by contending that monthly payments are not insurance (Chappell, 2017). It is just another way to pay for care, and eliminates insurance. DPC is not considered insurance in some states and DPC supporters are trying to pass state and federal legislation that declares their structure is not insurance. The rules and regulations prohibiting discrimination in insurance are then avoided. A counter to this position is that the fees are determined just as insurance is determined. The average 70 dollar monthly fee is what is needed to pay the bills just as a monthly premium given to an insurance company is what is determined will pay for care and be profitable. A better name for direct primary care might be "direct primary insurance".

Another potential problem with direct primary care is that physicians are isolated from other specialties. Patients are essentially paying ahead for all of their primary care services and they have to pay out of pocket for all or most of their specialty services or get additional insurance as required by the ACA. The insurance plans are commonly high deductible plans that require thousands of out of pocket expenses before insurance will pay. Patients have an incentive to get as much care as possible from their primary care providers to avoid paying additional out of pocket costs to specialists. As a result, physicians may feel pressured to go out of their area of expertise to address concerns that should be handled by specialists. For example, a DPC physician can be put in a compromising position if a patient needs hospitalization and yet refuses to go due to inability to pay. Separating payment for primary care from broader insurance exacerbates patients preferring what they already paid for.

DPC physicians can reply to this problem in three ways. The first is to point out that they are professionals and will not give advice or perform services outside of their expertise. One rejoinder is that without insurance companies, DPC practices will not be overseen. Insurance companies do provide a check on pro- 
viders by refusing to pay for inappropriate procedures. This oversight is lost with DPC and professionalism could suffer. Second, even in the fee for service model, there are pressures on physicians not to send patients to specialists. Referrals don't produce income. Financially, DPC physicians have an incentive to refer patients to others for expensive time-consuming care that they could competently provide themselves (Hoff, 2018). The incentive to limit care is a problem itself that all types of physicians and practices must address in various ways. DPC does so by promoting the amount of time they give to patients. Finally, Patients may worry that they are on their own when going to a specialist, but DPC practices often work with specialists to help out their patients. They coordinate care and work to get specialists to reduce prices for their cash paying patients, so the lower cost of care will continue when going to a specialist (Direct Primary Care Coalition, 2013). These arrangements can help lessen the pressures that they face from patients.

\section{Future Concerns}

If DPC continues to expand, there are other problems that need consideration. There are two ways to consider this approach. One is from a Kantian perspective. Kant thought that when determining whether a principle is just, we should ask: what if everyone did that? Could it be followed? Would we want everyone to follow that principle? For example, we should not lie, since communication would be impossible if everyone lied and we would not want others to lie. What if all primary care was direct primary care? The second is approach is consequential. What ethical complications will arise when DPC expands in an unregulated marketplace?

From a Kantian perspective, there is nothing contradictory from everyone having DPC. So, it is possible. The next thing to ask is whether we would be willing to have everyone avail of DPC? Generally, yes, but the young and healthy won't be willing to pay for a service that they don't plan on using. The lingering questions for universal DPC concern how everyone is going to pay for it and how it will be staffed. Analogously, it would be nice for everyone to have a Tesla. Having the resources for everyone to have one and everyone being able to pay for one is untenable. The current free market healthcare system makes universal DPC seem similarly undesirable and impossible.

From a free market approach, another concern is that a price war will develop. DPC came into existence to provide lower costs and better care for patients. But it doesn't appeal to everyone. It doesn't appeal to those unable to pay and the healthy who don't think that they will use it. To attract such patients, lower cost DPC plans might be developed for the poor and healthy. The plans could provide them limited care without the perks that make DPC sound so appealing to many. So, perhaps Costco and Walmart will offer plans that are twenty dollars a month and give a patient ten minutes with a physician up to once a month and bi-yearly physicals. Many young healthy people could be attracted to this ap- 
proach, even if they risk not getting the care they need when a serious illness arises. If such plans syphon off the young and healthy, then older and sicker patients would have higher monthly payments. The low 70 dollar monthly payments only work with a mix of young and old, and of healthy and sick patients.

The expansion of DPC will also lead to more physician shortages. It is possible that DPC advocates are right and more physicians will be attracted to primary care. Yet, if there is an increased flow of physicians to primary care, there will be a shortage of specialists. Either way, a system that has physicians caring for a third as many patients is going to exacerbate the physician shortage (Chappell, 2017).

\section{Lessons Learned}

The lessons learned from DPC can help to inform a more just health care system in the United States. DPC seems to be a more efficient way of providing care for patients by cutting out the profits and bureaucracy of insurance companies. It is affordable for many and it provides the care that patients need and want. Patients want to see their doctors when they want and as often as they want. Patients also like that DPC doctors are working to keep down the price of many drugs, tests, and trips to specialists. The problems are "market failures" or morally undesirable outcomes for society. DPC on its own leaves many patients without needed care and if it spreads, the numbers without care or with inadequate coverage will spread.

There is at least one other way to provide the benefits of DPC without the associated market failures. It is a non-market approach found in many countries that provide universal care. Universal health care does not leave anyone without coverage and it provides coverage for specialists and hospitalization too. A common feature of every universal system is similar to DPC: the elimination of for-profit insurance for basic coverage. For profit insurance is inefficient and costly. Either countries simply eliminate insurance companies as they do in England and Canada where the government is the sole insurance provider of basic universal coverage (individuals can and often do purchase additional private insurance for greater coverage), or they regulate insurance companies tightly as non-profits, as they do in Japan, France, and Germany. In either type of system, costly profits are eliminated, the system is simpler, and administrative costs are lower (Himmelstein et al., 2014).

A closer look at Japan's healthcare system can help to show how universal regulated coverage can achieve many of the benefits of DPC without encumbering harm and injustice to other parts of society. Japan covers everyone through a requirement that everyone have insurance from either employer based health care coverage or governmental health coverage paid through taxes. Two advantages of the Japanese system are that patients are able to see their doctor as often as they would like for as long as they would like, and so similar to DPC practices they end up seeing their doctors four times as often as the average patient in the 
United States. Also, as with DPC, administrative costs are four times lower than the United States average. They lower administrative costs by having non-profit insurance companies and standardized pricing for treatments and drugs set by a governmental committee every two years (Harden, 2009). They use regulation and the bargaining power of the government to lower prices rather than opting for a market solution. Every medical office knows exactly what will be paid for a procedure and it does not differ from insurer to insurer. Overall Japan spends about half as much on healthcare as the United States and from infant mortality to life expectancy has better health outcomes (WHO, 2017).

Japan's system also avoids the market pitfalls of DPC. First, medication, specialist care, and hospitalization are all covered. The DPC provider does not have to negotiate lower prices with specialists; a government committee does so. The physician is then able to focus on care rather than these business arrangements. Second, the government and non-profit insurance companies provide regulated oversight of medical practices. They have a mission to protect the public good, and have public accountability to ensure patients are protected to ensure good health and control costs. Thirdly, from the young and healthy to the old and sick, everyone is covered. Insurance is required for everyone. People pay via a percentage of their income at work and through taxes, rather than paying a set fee for everyone based upon their age. No one can be turned down for insurance, and if you lose your job, you don't lose your insurance. Finally, Japanese insurance covers specialists and hospitalization. Patients may go to specialists and the hospital for care and pay a small co-pay or nothing for treatment (NPR, 2008). The system is effective, affordable, efficient, accessible, and just.

A universal governmentally regulated system is not without its faults. While patients do get to see a physician when and how often they would like, they don't get extended appointments with their doctors. Doctors are paid less than in the United States and often feel rushed to see as many patients as they must see given the low reimbursements for office visits. Japan might look to a model like DPC to avoid this pitfall by offering monthly reimbursements for each patient. Although changing their current system in this way, given their health outcomes and their own physician shortages, seems unlikely. Finally, libertarians will argue that it is wrong to force people to have insurance. We are taking away people's ability to choose. The US Supreme court found that the requirement in the ACA was acceptable because health care insurance requirements are a type of tax and the government can tax people against their will for the overall good, and in the interests of individual citizens. Universal coverage is efficient and keeps citizens alive and healthier. Also, the government is protecting some who normally would take a risk and avoid insurance and those who never would be able to afford health insurance on their own. A good society, so the reasoning goes, limits economic freedom for health security. No one dies in Japan for lack of health insurance.

\section{Conclusion}

The DPC model is heralded as a free market approach to fixing the problems of 
primary care in the US. And it succeeds in providing high quality primary care without convoluted insurance intrusion and at reasonable costs. The problem is that success is for the lucky few while the rest are left out and public health is jeopardized. The successes and inherent problems with DPC point the US healthcare system to a non-market regulated universal system that reforms insurance, is also efficient, provides similar care, provides oversight, treats patients equally, and covers everyone. While not perfect, regulated universal health care systems provide a more ethically justified and similarly economically efficient approach.

\section{Conflicts of Interest}

The author declares no conflicts of interest regarding the publication of this paper.

\section{References}

AAMC (2017). New Research Reaffirms Physician Shortage. https://news.aamc.org/press-releases/article/workforce_projections_03142017/

Brekke, G. (2016). Direct Primary Care: Good for What Ails Us. Health Watch, 7-10.

Chappell, G. E. (2017). Health Care's Other "Big Deal”: Direct Primary Care Regulation in Contemporary American Health Law. Duke Law Journal, 66, 1331-1365.

Direct Primary Care Coalition (2013). FAQ on Direct Primary Care. https://directprimarycare.files.wordpress.com/2013/07/faqs-on-dpc.pdf

Eskew, P., \& Kathleen, K. (2015). Direct Primary Care: Practice Distribution and Costs across the Nation. Journal of the American Board of Family Medicine. https://www.jabfm.org/content/28/6/793

Harden, B. (2009). Japanese Health Care System Has Many Advantages, but May Not Be Sustainable. Washington Post.

http://www.washingtonpost.com/wp-dyn/content/article/2009/09/06/AR200909060163 $0 . \mathrm{html}$

Himmelstein, D. et al. (2014). A Comparison of Healthcare Administrative Costs in Eight Nations: The US Exceeds All Others by Far. Health Affairs. https://www.healthaffairs.org/doi/full/10.1377/hlthaff.2013.1327

Hoff, T. (2018). Direct Primary Care Has Limited Benefits for Physicians and Patients. STAT. https://www.statnews.com/2018/09/06/direct-primary-care-doctors-patients/

Klemes, A. et al. (2012). Personalized Preventative Care Leads to Significant Reductions in Hospitalization. The American Journal of Managed Care, 18. http://www.ajmc.com/journals/issue/2012/2012-12-vol18-n12/personalized-preventive -care-leads-to-significant-reductions-in-hospital-utilization

Krivich, R. S. (2017). What Closign Mean to the Direct Primary Care Model: Two Prominate Direct Pay Practices Are Shuting Their Doors, Prompting Questions about the Movements Future. Medical Economics, 94, 50-51.

Medscape (2017). Compensation Report. http://www.medscape.com/slideshow/compensation-2017-overview-6008547

NPR (2008). Japanese Pay Less for More Healthcare. http://www.npr.org/templates/story/story.php?storyId=89626309 
Page, L. (2013). The Rise and Furter Rise of Concierge Medicine. British Medical Journal. http://www.bmj.com/content/347/bmj.f6465

Porter, S. (2015). Significant Primary Care, Overall Physician Shortage Predicted by 2025. http://www.aafp.org/news/practice-professional-issues/20150303aamcwkforce.html

Ramsey, L. (2017). A New Kind of Doctor's Office Charges a Monthly Fee and Doesn't Take Insurance and It Could Be the Future of Medicine. Business Insider.

https://www.businessinsider.com/direct-primary-care-a-no-insurance-healthcare-mod el-2017-3

Sinsky, C. et al. (2016). Allocation of Physician Time in Ambletory Practice: A Time and Motion Study in Four Specialties. Annals of Internal Medicine, 165, 753-760.

WHO (2017). World Health Organization Countries. http://www.who.int/countries/en/

Wilper, A. et al. (2009). Health Insurance and Mortality in US Adults. American Journal of Public Health, 99, 2286-2295. https://doi.org/10.2105/AJPH.2008.157685

Zamosky, L. (2014). Direct-Pay Medical Practices Could Diminish Payer Headaches. Medical Economics.

http://medicaleconomics.modernmedicine.com/medical-economics/content/tags/conci erge-service/direct-pay-medical-practices-could-diminish-payer-h 